\title{
Exhaled nitric oxide and bronchial responsiveness in healthy subjects exposed to organic dust
}

\author{
B-M. Sundblad, B-M. Larsson, L. Palmberg, K. Larsson
}

Exhaled nitric oxide and bronchial responsiveness in healthy subjects exposed to organic dust. B-M. Sundblad, B-M. Larsson, L. Palmberg, K. Larsson. (C)ERS Journals Ltd 2002.

ABSTRACT: Inhalation of organic dust from swine houses causes an intense inflammatory reaction in the respiratory tract, and increased bronchial responsiveness to methacholine in healthy subjects. The aims of the present study were to investigate whether exhaled nitric oxide (NO) is a marker of the inflammation caused by exposure to organic dust (swine dust), whether there is a relationship between an increase in exhaled NO and bronchial responsiveness, and also whether wearing a half-mask influences the airway reaction (assessed by exhaled NO) and the increased bronchial responsiveness.

Thirty-three healthy nonatopic, nonsmoking subjects were exposed during $3 \mathrm{~h}$ of light work in a swine confinement building. Eleven of the subjects were wearing a half-mask and 22 were unprotected. Lung function, bronchial responsiveness and exhaled NO were measured before and after exposure.

The provocative concentration causing a $20 \%$ fall in forced expiratory volume in one second fell by 2.7 (2.1-4.1) (median (25th-75th percentiles)) doubling concentration steps in subjects without a half-mask and by $1.5(0.9-2.9)$ doubling concentration steps in subject wearing a mask. Exhaled NO increased from $7.5(5.7-13.7)$ parts per billion (ppb) before to $13.4(10.5-17.5) \mathrm{ppb}$ after exposure in the unprotected group and was unaltered (8.3 (6.1-14.1) to 8.6 (6.6-14.6) $\mathrm{ppb})$ in the group wearing a half-mask. There was no correlation between NO increase and provocative dose causing a $20 \%$ fall in the forced expiratory volume in one second decrease.

In conclusion, bronchial responsiveness and exhaled nitric oxide increased after exposure to a swine confinement facility. Half-mask abolished the increase in exhaled nitric oxide levels, but influenced the increase in bronchial responsiveness to a minor extent. These results indicate that these two outcome measures reflect different aspects of airway inflammation induced by exposure to a farming environment.

Eur Respir J 2002; 20: 426-431.
Lung and Allergy Research, National Institute of Environmental Medicine, Karolinska Institutet, Stockholm, Sweden.

Correspondence: B-M. Sundblad Lung and Allergy Research

National Institute of Environmental Medicine

Karolinska Institutet

S-171 77 Stockholm

Sweden

Fax: 468300619

E-mail: Britt-Marie.Sundblad@,

imm.ki.se

Keywords: Bronchial provocation exhaled nitric oxide methacholine

organic dust

\section{Received: July 22001}

Accepted after revision: February 28 2002

This study was supported by The Swedish Heart-Lung Foundation.
Endogenously produced nitric oxide (NO) in exhaled air of animals and humans was first measured by GUSTAFSSON et al. [1], and it was suggested early that the concentration of exhaled NO may reflect airway inflammation, thus offering a noninvasive method to assess inflammatory airway diseases [2-4]. Following a bronchial allergen challenge there is an elevation of exhaled NO levels in allergic patients and increased levels of exhaled NO are also observed in acute exacerbations of asthma [5-7]. Endotoxin and several inflammatory cytokines, such as tumour necrosis factor- $\alpha$ (TNF- $\alpha$ ), interferon- $\gamma$ and interleukin (IL)-1 induce transcription of NO by inducible NO synthase (iNOS) [3,8], which is generated as a response to inflammation or tissue injury.

Exposure to a swine confinement building for $3 \mathrm{~h}$ causes airway inflammation in healthy nonatopic subjects. Symptoms like fever and malaise are common. The exposure also increases bronchial responsiveness to methacholine and induces release of cytokines (e.g. TNF- $\alpha$ and IL-6, IL-1, IL-8) into the airways [9-13].
The aims of the present study were to investigate whether exhaled NO is a marker of the inflammation caused by exposure to the environment in swine confinement buildings and if there is a relationship between two inflammatory indices, the increase in bronchial responsiveness to methacholine and the level of exhaled NO. Furthermore, the aim was to find out whether wearing a half-mask influences the respiratory response to dust exposure.

\section{Material and methods}

\section{Study subjects}

Thirty-three healthy, nonatopic, nonsmoking subjects (14 males) with a mean age of 26 yrs (range 20-47) were exposed for $3 \mathrm{~h}$, while weighing pigs, in a swine confinement building.

None of the subjects had a history of asthma, as assessed by a questionnaire, and all denied ongoing respiratory infections. All subjects gave their informed 
consent and the study was approved by the ethics committee at the Karolinska Institute, Stockholm, Sweden.

\section{Study design}

One week prior to the exposure, lung function, bronchial responsiveness and exhaled NO were measured. The subjects were randomised to wear a halfmask $(n=11)$, with a class P2 filter $(9322 ; 3 \mathrm{MTm}$, Upplands Vasby, Sweden), or not to wear a mask $(n=22)$ during exposure. The characteristics of the subjects were similar in the two groups.

Exposure took place in a swine confinement building with approximately 300 pigs, and five or six subjects were exposed on each occasion. Exposure was measured with personal samplers.

Exhaled NO was measured $5 \mathrm{~h}$ after the beginning of the exposure, and lung function and bronchial responsiveness to methacholine $2 \mathrm{~h}$ later. In eleven of the subjects without mask, exhaled NO measurements were repeated after the methacholine challenge and after inhalation of salbutamol $(0.8 \mathrm{mg}$, Diskhaler; Ventoline(R).

Symptoms such as shivering, headache, malaise, muscle pain and nausea were assessed before and after the visit to the swine confinement building. Oral temperature was measured before and every other hour following exposure.

\section{Spirometry}

Vital capacity (VC), forced expiratory volume in one second (FEV1) and airway resistance (Raw) were measured using a body plethysmograph (Eric Jaeger GmbH \& Co, Würzburg, Germany). Spirometry was performed according to the American Thoracic Society recommendations and the best of at least three measurements was recorded [14]. FEV1 was measured before and following inhalation of methacholine with a wedge spirometer (Vitalograph $\AA$, Buckingham, UK).

\section{Methacholine provocation test}

Bronchial challenge with methacholine was performed with a Sidestream jet nebuliser (Medic-Aid, Pagham, UK). In order to increase the methacholine deposition in the lower airways, the nebulisate was led through a drying device, where the aerosol was dried for about $8 \mathrm{~s}$ before inhalation [15, 16]. Inhalation time $(2 \mathrm{~s}$, i.e. a volume of $0.8 \mathrm{~L})$, and number of breaths $\left(15 \mathrm{~min}^{-1}\right)$ were controlled using a metronome. The inhalation flow was controlled by the use of a back valve at the outlet of the tube.

Methacholine inhalations were performed during $1 \mathrm{~min}$, i.e. $30 \mathrm{~s}$ of inhalation and $30 \mathrm{~s}$ of exhalation, at each concentration and FEV1 was measured 4 min after the start of the inhalation. There were $6 \mathrm{~min}$ between the start of the inhalations of two successive concentrations. The subjects inhaled diluent followed by methacholine $\left(0.5,1,2,4,8,16,32 \mathrm{mg} \cdot \mathrm{mL}^{-1}\right)$. Only one FEV1, i.e. one forced expiration, was allowed at each dose step. The provocation concentration causing a 20\% fall in FEV1 (PC20) and the provocation dose causing a 20\% fall in FEV1 (PD20) were calculated. The PC/PD calculations were performed by interpolation on a logarithmic scale of concentration or cumulated dose of methacholine, respectively. The dose/response slope (DRS) of change in FEV1 was calculated by linear regression including all data points, using the per cent change of FEV1 (initial value as the average of pre and postdiluent value) as a function of the cumulated methacholine dose [17].

\section{Exhaled nitric oxide}

Exhaled NO was determined during single-breath exhalations $[2,18,19]$. The subject inhaled NO-free air via a mouthpiece to total lung capacity, followed immediately by full exhalation, with a flow rate of about $100 \mathrm{~mL} \cdot \mathrm{s}^{-1}$, through the mouthpiece into the the apparatus. During exhalation, an excess pressure was created in the oral cavity, which ensures closure of the velum and prevents contamination of the sample with nasal air. Nitric oxide was measured with chemiluminescence after reaction with ozone in the Aerocrine NO-system (type EBA:I; Aerocrine AB, Stockholm, Sweden). The mean of three measurements was considered for evaluation. To reduce contamination from the oral cavity, subjects used a mouthwash with sodium bicarbonate $(10 \%)$ for $1 \mathrm{~min}$ before the measurement [20].

\section{Symptoms}

Symptoms were evaluated on a visual analogue scale (VAS, 0-100 $\mathrm{mm}$ ) where zero represented no symptoms and $100 \mathrm{~mm}$ unbearable or very strong symptoms. The subject was requested to put a cross on the scale. The length, between the zero point and the cross, was measured and the difference before and after exposure was calculated.

\section{Exposure measurement}

IOM samplers equipped with filter cassettes $(25 \mathrm{~mm}$; Institute of Occupational Medicine, SKC Ltd, Dorset, UK) and portable pumps (SKC Ltd) were used to monitor inhalable dust levels, and the cassettes were equipped with polycarbonate filters (pore size $0.4 \mu \mathrm{L}$ ) (Millipore, Sundbyberg, Sweden). Each subject carried the samplers in the breathing zone. The airflow was measured with a rotameter before and after sampling and adjusted to $2 \mathrm{~L} \cdot \mathrm{min}^{-1}$. Inhalable dust was measured by a normal weighing procedure, after $24 \mathrm{~h}$ of conditioning, using a Mettler $(\mathbb{R}$ ME22 balance (Mettler, Greisensee, Switzerland) and reference filter.

\section{Statistical analysis}

Results are presented as mean (SD or 95\% confidence interval $(\mathrm{CI})$ ) or median values $(25$ th- -75 th 
percentiles). Statistical comparisons were assessed by t-test for paired observations (lung function) and the Wilcoxon's signed rank-sum test (symptoms, bronchial responsiveness and NO values) within groups. Analysis of variance (ANOVA) and Mann-Whitney U-tests were used when groups were compared. A p-value $<0.05$ was considered significant.

\section{Results}

Body temperature increased in all but four subjects after exposure to organic dust $\left(0.4(0.29-0.55)^{\circ} \mathrm{C}(95 \%\right.$ CI), $\mathrm{p}<0.001)$. Symptoms like shivering, headache and malaise increased significantly $(\mathrm{p}<0.005)$, and one subject also reported muscle pain. There was no significant difference in reported symptoms or temperature between subjects with and without mask. The median (25th-75th percentiles) inhalable dust level was $9.9 \mathrm{mg} \cdot \mathrm{m}^{-3}(8.6-14.6)$.

Lung function was normal in both groups: VC 94 (10) and 95 (6) \% predicted; total lung capacity 95 (9) and 96 (8) \% pred; and FEV1 98 (11) and 100 (9) \% pred, in subjects without and with the half-mask, respectively. Following exposure to organic dust VC decreased by $\sim 2 \%$ in both groups and there was a decrease in FEV 1 of $2.7 \%$ in the protected group $(p=0.002)$ and $6 \%$ in the group without mask $(\mathrm{p}<0.001)$. There was no significant change in airway resistance in either group.

Exposure induced an increase in bronchial responsiveness to methacholine; PD20 fell from 3.3 (2.6-14.1) to $1.0(0.39-2.8) \mathrm{mg}$ in subjects wearing the mask $(\mathrm{p}=0.005)$ and from $1.8(0.77-9.0)$ to $0.2(0.10-0.45)$ $\mathrm{mg}$ in subjects without mask $(\mathrm{p}=0.0001)$. The slope increased from $5.7(1.4-8.2)$ to $18.6(9.9-54.6) \% \cdot \mathrm{mg}^{-1}$ ( $\mathrm{p}=0.003)$ with mask and from $13.7(2.1-27.0)$ to 91.8 (38.8-209.6) \% $\mathrm{mg}^{-1}(\mathrm{p}=0.0002)$ without mask (fig. 1).

There was no significant difference between the two groups with regard to the change of concentration steps $(\mathrm{p}=0.07)$.

Exhaled NO increased from 7.5 ( 5.7-13.7) ppb before exposure to 13.4 (10.5-17.5) ppb $5 \mathrm{~h}$ after exposure $(p=0.0001)$ in the group without the mask. In the group with mask exhaled NO did not change significantly, $8.3(6.1-14.1) \mathrm{ppb}$ before and $8.6(6.6-14.6)$ after exposure, $(\mathrm{p}=0.48$, fig. 2$)$. There was a significant difference between the two groups with regard to the NO response $(\mathrm{p}=0.006)$.

In 11 subjects without mask, exhaled NO was measured repeatedly. Exhaled NO level was 6.6 (5.5-7.4) ppb at baseline, 14.1 (11.8-17.8) ppb $5 \mathrm{~h}$ after exposure and 14.0 (11.8-19.2) $\mathrm{ppb} 7 \mathrm{~h}$ after exposure. The methacholine challenge induced a small decrease in NO before $(\mathrm{p}=0.06)$ and after $(\mathrm{p}=0.01)$ exposure. Inhalation of salbutamol did not significantly further alter the levels of exhaled NO. Exhaled NO measured after inhalation of the $\beta_{2}$ agonist on the exposure day was still significantly increased compared to baseline pre-exposure values ( $\mathrm{p}=0.003)$ (fig. 3).

There was no significant correlation between the increase in bronchial responsiveness and exhaled NO following exposure to organic dust ( $\mathrm{r}=0.08, \mathrm{p}=0.44)$.
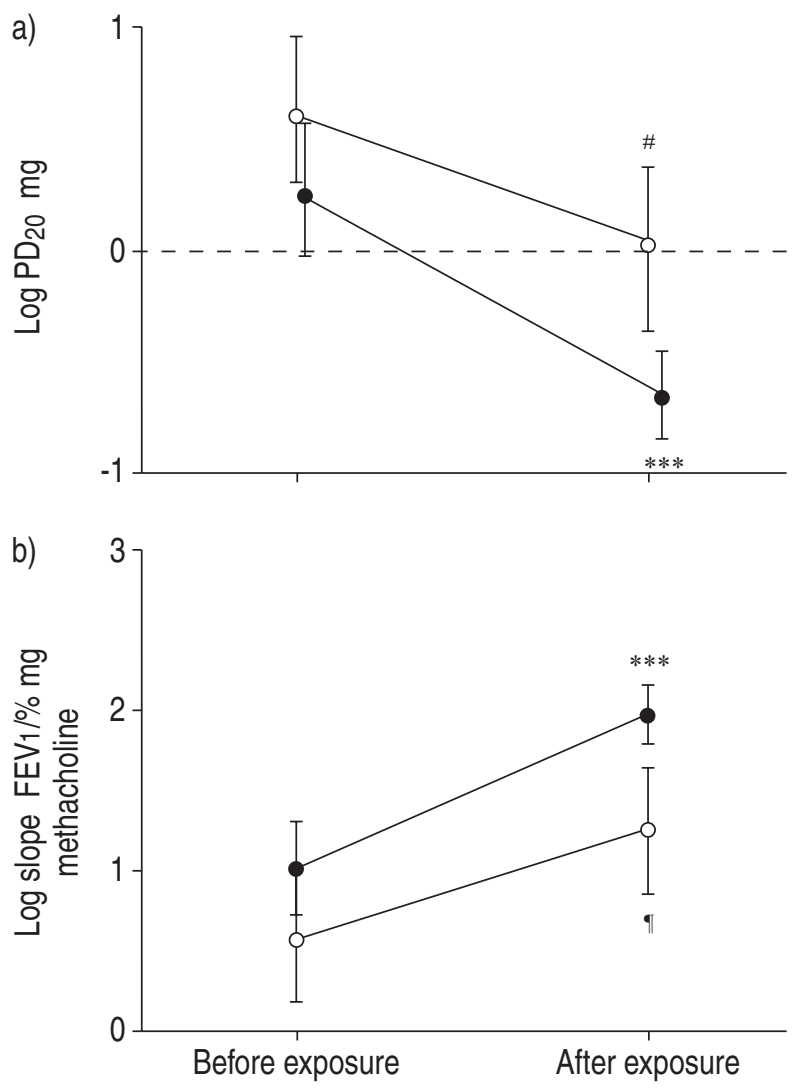

Fig. 1.-Bronchial responsiveness to methacholine, before and after exposure to a swine confinement building in subjects wearing a half-mask $(\bigcirc)$ and subjects without a half-mask $(\bullet)$. Data are presented as mean $\pm 95 \%$ confidence intervals. PD20: provocative dose causing a $20 \%$ fall in forced expiratory volume in one second (FEV1). There were no significant differences between the groups. ***: $\mathrm{p}<0.001 ;{ }^{\#}: \mathrm{p}=0.005 ;{ }^{\uparrow}: \mathrm{p}=0.003$.

\section{Discussion}

In this study it has been demonstrated that exposure to swine dust is associated with increased levels of

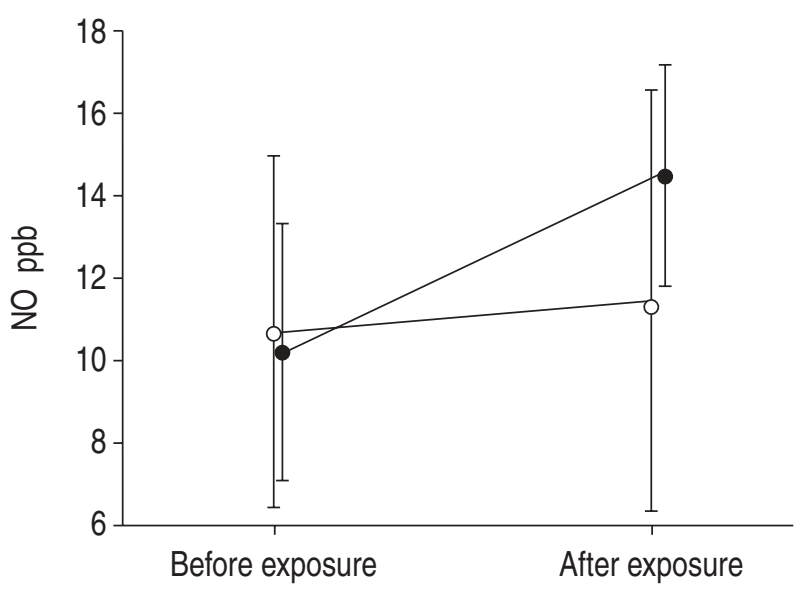

Fig. 2.-Exhaled nitric oxide (NO), before and after exposure to a swine confinement building in subjects wearing a half-mask $(\bigcirc, \mathrm{NS})$ and subjects without a half-mask $(\boldsymbol{O}, \mathrm{p}=0.0001)$. Data are presented as mean $\pm 95 \%$ confidence intervals. $\mathrm{p}=0.006$ between groups. 


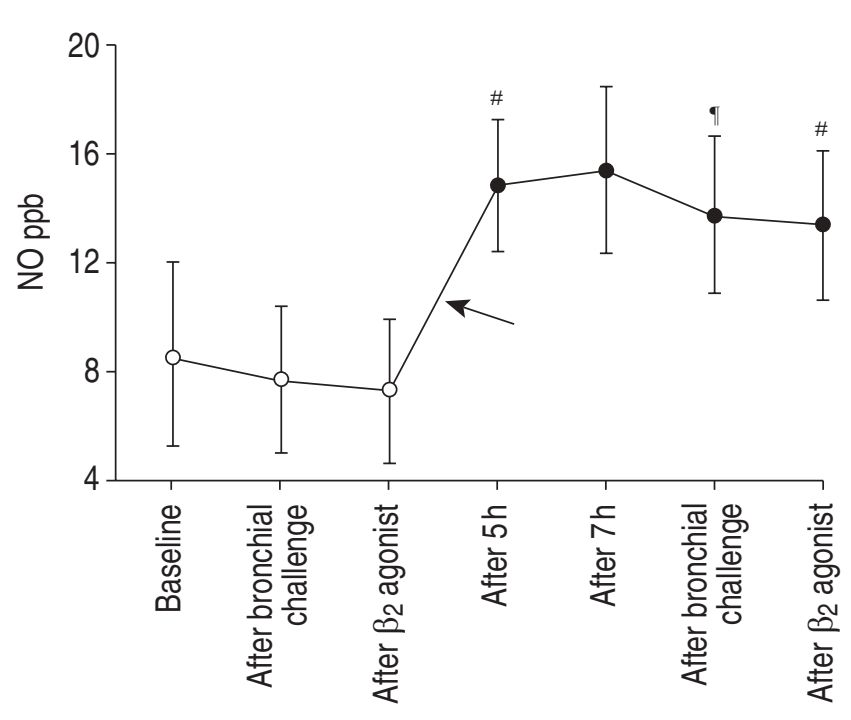

Fig. 3.-Exhaled nitric oxide (NO) levels before and after methacholine challenge and inhalation of $\beta_{2}$ agonist before and after exposure to a swine confinement building (arrow). Data are presented as mean $\pm 95 \%$ confidence intervals. ${ }^{*}: p=0.003$ compared with baseline; ": $\mathrm{p}=0.01$ compared with the value obtained $7 \mathrm{~h}$ after exposure.

exhaled NO and increased bronchial responsiveness to methacholine and that there is no relationship between these two findings. Protection with half-mask inhibits the increase of exhaled NO whereas the increase in bronchial responsiveness is influenced only to a minor extent.

In the present study, it has been demonstrated that NO levels are approximately doubled in subjects exposed to a swine confinement facility. Increased levels of NO may indicate an induction of bronchoalveolar iNOS induced by exposure, which in turn induces production of pro-inflammatory cytokines in a variety of cells. The inflammatory reaction after acute exposure to organic dust, with increased number of neutrophils, macrophages and activated lymphocytes, in healthy subjects is similar to the inflammation observed in patients with chronic bronchitis [21, 22]. This is in accordance with the finding that repeated exposure to the farming environment leads to the development of airway disease, especially chronic bronchitis, in pig farmers [23, 24].

KöLBECK et al. [25] were not able to show increased levels of exhaled NO following exposure to dust in a swine confinement building. Different techniques and a more standardised procedure to determine exhaled NO in the present study could possibly explain the discrepancies. Furthermore, in another study where subjects performed a nasal challenge with swine confinement dust, slightly elevated levels of exhaled NO were demonstrated [26]. In that study exhaled NO increased within the first hour after exposure, indicating a rapid induction of NO. In the present study, for practical reasons, exhaled NO was measured $5 \mathrm{~h}$ after the beginning of exposure in the confinement building. The NO levels at that time point were almost identical to the NO values, measured $2 \mathrm{~h}$ later.
Methacholine challenge decreased exhaled NO both before and $7 \mathrm{~h}$ after the exposure. Bronchial challenge with methacholine has not been shown previously to alter the levels of exhaled NO in asthmatic subjects [27, 28]. However, KOLBECK et al. [25] demonstrated decreased levels of exhaled NO after histamine provocation in healthy subjects exposed to dust. DEYKIN et al. [29] showed a fall in exhaled NO levels after repeated spirometries in subjects with atopic asthma and also showed that hyperventilation and physical exercise increased the NO production but decreased the concentration of exhaled $\mathrm{NO}$ in healthy nonasthmatic subjects $[30,31]$. A possible explanation for the decrease in exhaled NO levels after methacholine challenge in the present study could thus be deep breaths performed prior to the FEV1 measurements during the methacholine provocation challenge.

Inhalation of salbutamol after the methacholine provocation test did not influence the level of exhaled NO in subjects with ongoing inflammatory airway reaction due to exposure to organic dust. This is in accordance with findings in asthmatic subjects where regular use of short and long-acting $\beta_{2}$ agonists did not alter the levels of exhaled NO [32].

Wearing a half-mask attenuated the increase of exhaled NO and bronchial responsiveness due to exposure. In subjects using half-mask, the bronchial responsiveness increased significantly by approximately 1.5 doubling concentration steps, whereas exhaled NO remained unchanged after exposure. Particles and microbial agents stimulate NO production, and NO contributes to the chemical defence mechanisms that keep the airways free from microorganisms [33]. The half-mask filters particles and bacterial components and it completely abolished the increase of exhaled NO-levels following exposure whereas, the influence of the mask on the increase of bronchial responsiveness was minor. This suggests that other components than particles may be responsible for the increased bronchial responsiveness. In accordance with the present findings Dosman et al. [34] recently demonstrated a minor, but significant, increase in bronchial responsiveness in subjects protected with mask and a greater increase in subjects without mask when exposed to swine dust.

A high correlation between exhaled NO and airway hyperresponsiveness have been demonstrated in both mild and severe asthma [35-37]. In the present study, no relationship between increases of exhaled NO and bronchial responsiveness in healthy subjects, following exposure in a swine confinement building, were found. Recently, in a population study, the current authors have demonstrated a significant correlation between exhaled NO levels and bronchial responsiveness to methacholine in subjects with asthma but not in healthy subjects [38]. In that study the methodology was identical to that used in the present study. Thus, the increased response to methacholine and exhaled NO may reflect different aspects of airway inflammation in healthy subjects. In asthma, it is likely that the inflammation causes bronchial hyperresponsiveness and that NO should be regarded as a marker of airway inflammation rather than as an endogenous 
modulator of bronchial tone $[27,39,40]$. In subjects exposed to organic dust this seems not to be the case.

In conclusion, bronchial responsiveness and exhaled nitric oxide increases after exposure to organic dust. The half-mask inhibited the increase in exhaled nitric oxide levels but had a minor effect on the increase of bronchial responsiveness to methacholine. The current findings indicate that exhaled nitric oxide and increased bronchial responsiveness to methacholine reflect different aspects of airway inflammation in this model.

Acknowledgements. The authors would like to thank S. Siljerud, F. Acevedo and C. Kallin for their excellent technical assistance.

\section{References}

1. Gustafsson L, Leone A, Persson M, Wiklund N, Moncada S. Endogenous nitric oxide is present in the exhaled air of rabbits, guinea-pigs and humans. Biochem Biophys Res Commun 1991; 181: 852-857.

2. ATS. Recommendations for standardized procedures for the online and offline measurement of exhaled lower respiratory nitric oxide and nasal nitric oxide in adults and children-1999. Am J Respir Crit Care Med 1999; 160: 2104-2117.

3. Barnes P. Nitric oxide and airway disease. Ann Med 1995; 27: 389-393.

4. Hedenstierna G, Hogman M. Can exhaled NO be used as a marker of airway inflammation. Eur Respir $J$ 1998; 12: 1248-1249.

5. Alving K, Weitzberg E, Lundberg J. Increased amount of nitric oxide in exhaled air of asthmatics. Eur Respir J 1993; 6: 1368-1370.

6. Kharitonov S, Yates D, Robbins R, Logan-Sinclair E, Barnes P. Increased nitric oxide in exhaled air of asthmatic patients. Lancet 1994; 343: 133-135.

7. Barnes P, Liew F. Nitric oxide and asthmatic inflammation. Immunol Today 1995; 16: 128-130.

8. Zopol W, Rimar S, Gillis N, Marletta M, Bosken C. Nitric oxide and the lung. Am J Respir Crit Care Med 1994; 149: 1375-1380.

9. Malmberg P, Larsson K. Acute exposure to swine dust causes bronchial hyperresponsiveness in healthy subjects. Eur Respir J 1993; 6: 400-404.

10. Larsson K, Eklund A, Hansson L, Isaksson B-M, Malmberg P. Swine dust causes intense airways inflammation in healthy subjects. Am J Respir Crit Care Med 1994; 150: 973-977.

11. Wang Z, Larsson K, Palmberg L, Malmberg P, Larsson P, Larsson L. Inhalation of swine dust induces cytokine release in the upper and lower airways. Eur Respir J 1997; 10: 381-387.

12. Larsson B-M, Larsson K, Malmberg P, Palmberg L. Gram positive bacteria induce IL-6 and IL-8 production in human alveolar macrophages and epithelial cells. Inflammation 1999; 23: 217-230.

13. O'Sullivan S, Dahlen SE, Larsson K, et al. Exposure of healthy volunteers to swine house dust increases formation of leukotrienes, prostaglandines $\mathrm{D}_{2}$, and bronchial responsiveness to methacholine. Thorax 1998; 53: 1041-1046.
14. ATS. Standardization of spirometry. Am J Respir Crit Care Med 1994; 152: 1107-1136.

15. Eklund L, Sundblad B-M, Malmberg P, Larsson K. The salt output of a nebulizer - a comparison between two nebulizer types. Resp Med 2000; 94: 139-144.

16. Malmberg P, Larsson K, Thunberg S. Increased lung deposition and biological effect of methacholine by use of drying device for bronchial provocation tests. Eur Respir J 1991; 4: 890-898.

17. Chinn S. Methodology of bronchial responsiveness. Thorax 1998; 53: 984-988.

18. Lundberg JON, Weitzberg E, Lundberg JM, Alving K. Nitric oxide in exhaled air. Eur Respir J 1996; 9: 2671-2680.

19. Kharitonov S, Alving K, Barnes PJ. Exhaled and nasal nitric oxide measurements: recommendations. Eur Respir J 1997; 10: 1683-1693.

20. Zetterquist W, Pedroletti C, Lundberg JON, Alving K. Salivary contribution to exhaled nitric oxide. Eur Respir J 1999; 13: 327-333.

21. Delen F, Sippel J, Osborne M, Law S, Nundhini T, Holden W. Increased exhaled nitric oxide in chronic bronchitis. Chest 2000; 117: 695-701.

22. Maziak W, Loukides S, Culpitt S, Sullivan P, Kharitonov S, Barnes P. Exhaled nitric oxide in chronic obstructive pulmonary disease. Am J Respir Crit Care Med 1998; 157: 998-1002.

23. Rylander R, Donham K, Hort C, Brouwer R, Heederick D. Effects of exposure to dust in swine confinement buildings: a working group report. Scand $J$ Work Environ Health 1989; 15: 309-312.

24. Vogelzang $P$, van der Gulden J, Folgering $H$, Heederick D, Tielen M, van Schayck C. Longitudinal changes in bronchial responsiveness associated with swine confinement dust exposure. Occup Environ Lung Dis 2000; 117: 1488-1495.

25. Kölbeck K-G, Ehnhagen A, Juto J-E, et al. Airway reactivity and exhaled $\mathrm{NO}$ following swine dust exposure in healthy volunteers. Resp Med 2000; 94: $1065-1072$.

26. Kirsten A, Jorres R, Kirsten D, Magnussen H. Effect of nasal challenge with endotoxin-containing swine confinement dust on nasal nitric oxide production. Eur J Med Res 1997; 2: 335-339.

27. Gamier P, Fajac I, Dessanges J, DallAva-Santucci A, Lockhart A, Dinh-Xuan A. Exhaled nitric oxide during acute changes of airway calibre in asthma. Eur Respir J 1996; 9: 1134-1138.

28. Deykin A, Belostokotsky O, Hong C, Massaro A, Lilly $\mathrm{C}$, Israel $\mathrm{E}$. Exhaled nitric oxide following leukotriene $\mathrm{E}_{4}$ and methacholine inhalation in patients with asthma. Am J Respir Crit Care Med 2000; 162: 1685-1689.

29. Deykin A, Halpern O, Massaro A, Drazen J, Israel E. Expired nitric oxide after bronchoprovocation and repeated spirometry in patients with asthma. Am J Respir Crit Care Med 1998; 157: 769-775.

30. Persson M, Wiklund P, Gustafsson E. Endogenous nitric oxide in single exhalations and the change during exercise. Am Rev Respir Dis 1993; 148: 12101214.

31. Riley M, Pórszász J, Miranda J, Engelen M, Brundage B, Wasserman K. Exhaled nitric oxide during exercise in primary pulmonary hypertension and pulmonary fibrosis. Chest 1997; 111: 44-50.

32. Yates D, Kharitonov P, Barnes P. Effect of short- and long-acting inhaled $\beta_{2}$-agonists on exhaled nitric oxide 
in asthmatic patients. Eur Respir J 1997; 10: 1483 1488.

33. Diamond G, Legarda D, Ryan L. The innate immune response of the respiratory epithelium. Immunol Rev 2000; 173: 27-38.

34. Dosman J, Senthilselvan A, Kirychuk S, et al. Positive human health effects of wearing a respirator in a swine barn. Chest 2000; 118: 852-860.

35. Al-Ali MK, Eames C, Howarth PH. Exhaled nitric oxide; relationship to clinicophysiological markers of asthma severity. Respir Med 1998; 92: 908-913.

36. Dupont L, Rochette F, Demedts G, Verleden G. Exhaled nitric oxide correlates with airway hyperresponsiveness in steroid-naive patients with mild asthma. Am J Respir Crit Med 1998; 157: 894-898.

37. Jatakanonen A, Lim S, Kharitonov SA, Chung KF,
Barnes PJ. Correlation between exhaled nitric oxide, sputum eosinophils, and methacholine responsiveness in patients with mild asthma. Thorax 1998; 53: 9195.

38. Sundblad B-M, Ericsson I, Gustafsson L, Larsson K. Exhaled nitric oxide (NO) and bronchial responsiveness in a population study. Eur Resp J 1999; 14: Suppl. $30, \mathrm{~S} 170$.

39. Högman M, Frostell C, Hedenström H, Hedenstierna G. Inhalation of nitric oxide modulates adult human bronchial tone. Am Rev Respir Dis 1993; 148: 1474 1478.

40. Sanna A, Kurtansky A, Veriter C, Stanescu D. Bronchodilator effect of inhaled nitric oxide in healthy men. Am J Respir Crit Care Med 1994; 150: 1702-1704. 